\title{
GREENING OF INDUSTRY NETWORK NEWS
}

\section{NETWORK MISSION}

The mission of the Greening of Industry Network is to stimulate, coordinate and promote research of high quality, relevance and usefulness toward ensuring that the activities of industry - including business, labour, consumers, government and others - are consistent with building a sustainable future.

Network participation is open to all and includes interested individuals from many fields, sectors and countries who respond to the themes and issues the Network poses. Level of participation depends upon individuals' interests and availability. Currently the Network comprises nearly 600 individuals representing academia, business, public interest, labour and government from 25 countries. Participants work together to build policies and strategies towards creating a sustainable future through many vehicles - coordinated research efforts, co-authored publications, planning and participating in workshops, public forums and conferences.

\section{MEMBERSHIP SURVEY}

In March of this year, we sent a survey to all Network participants asking what they see as the key elements and functions of the Greening of Industry Network and to assess whether we are providing needed and useful products. We asked participants to list their areas of interest and research and to further define how they would like to participate in the Network. Two years ago we posed a similar set of questions, and the responses were instrumental in defining Network goals and activities. Since then, our participation increased greatly, and there has been an increased interest in issues concerning industry and the environment and shifts in the way researchers and practitioners are approaching these issues.

To date, 209 people, or about 36 per cent of the Network, have responded to the 1994 survey. Of these, almost 80 per cent (166) said that they wish to be active members (as opposed to only receiving news). We were especially pleased to hear from 70 respondents who volunteered to plan conferences and workshops and write editorials and book reviews for this NoticeBoard. We will draw on this volunteer pool to form a Network program and planning committee. Our active participants represent 23 different countries ranging from Lithuania to Venezuela to Australia - far beyond our 1991 beginnings in Western Europe and the US. Their fields include management and organisational theory, accounting and finance, political science, socially responsible investing, education, clean technology and production, strategic planning, and corporate environmental policy to name a few. Respondents cited their affiliations with over 70 other organisations around the world. We are using these responses to guide the development of our 10-year agenda begun in 1991. If you would like to complete a questionnaire and participate in the Greening of Industry Network, please contact either Network coordinator.

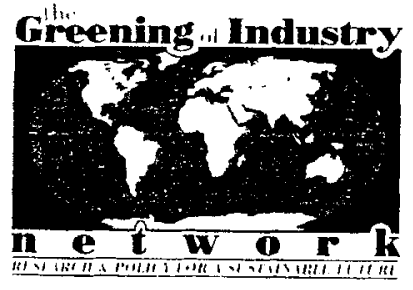

\section{NETWORK ACTIVITIES UPDATE}

'What Role for Industry in a Sustainable World?'

Public forum, Amsterdam, The Netherlands, April 28, 1994

On April 28, 1994, the Greening of Industry Network hosted a debate, What Role for Industry in a Sustainable World?, at Amsterdam's renowned cultural cafe, DeBalie. About 80 people took part in the discussion moderated by Dutch professor Eric Jan Tuininga (Free University, Amsterdam). Network advisory board members Tom Gladwin (New York University), Mark Joyce (US Environmental Protection Agency), and Harry Spaas (Dow, Europe) were the panellists in the debate. Professor Wim Hafkamp (KPMG Milieu and Catholic University Brabant, Tilburg) started the debate with a challenge to 'the greening of industry'. The following is a synopsis of discussion points and questions.

Is the 'greening' of industry an add-on issue or a broader social issue that integrates other issues? If it is a broader issue, then value setting is part of the process. 'Caring capitalism' must address the full agenda. Sustainable development needs to integrate 'limits thinking'. Its aim should not be to make existing systems more efficient, but rather to set absolute limits. If that is the case, -we need values. Management systems put in place to create more efficiency do not ask questions about values. Thus, we must see environmental issues through an ethical lens as well. For example, if the challenge is to reduce the use of cars and fossil fuels, the main questions become 'Will the dealer heal the addict?', 'Can we ask the car industry to kill itself?' 'Is it possible to make money selling less?', 'Is economic growth always material growth?'

Discussion around these points identified several trends which are contradictory to creating green, or sustainable industry. These are just-in-time production, world-wide sourcing and the globalisation of production. These trends will lead to more pollution and degradation. In addition, participants noted that technical innovations often contribute to unemployment, which as an issue, takes precedence for most policy makers over environmental issues. They also noted that presently, if firms act in an environmentally benign way, there is no guarantee that they will succeed in business. A firm's environmental record, manifested through environmental reporting, could be used not only as a device to enhance accountability, but also help to develop a new tax system which would stimulate sustainable development. The challenge then is to develop full cost. accounting systems.

Some feel that sustainable management is a model for the long-term future. In the present, we need to take small steps. Creating a sustainable society is a search-and-learning process. It is difficult now to identify the sustainable enterprise - we do not know yet what it will look like. However, it is clear that the process towards achieving it should involve coalitions between business and other social groups. Coalitions are important not only to involve broadbased support, but also because all stakeholders involved may possess parts of the solution. In addition, all 
stakeholders have certain responsibilities towards achieving sustainability, and therefore should be challenged to meet those responsibilities.

When assessing firms for sustainability, we must recognise their position. Some firms can earn money through niche marketing (i.e. The Body Shop) while others do not have that opportunity. The role of capital markets was discussed at length. At present, it is very difficult to secure green venture capital. Business lacks a general knowledge of ecosystems and the environment. The importance of language and development of new concepts in creating sustainability were also discussed. New language and concepts will help to create a new horizon and creative thinking.

Overall, discussion was exciting and interesting, engaging the audience as well as the panellists and commentators. This event was the first in a series of international workshops and debates the Network plans to host in the upcoming years.

\section{INTERNATIONAL ADVISORY BOARD MEETING}

April 27-28, 1994, Amsterdam, The Netherlands.

The Network Advisory Board met with Network coordinators, conference organisers, and representatives of Business Strategy and the Environment in April in Amsterdam to discuss long-term vision and mission and to review activity plans for the coming year. Professor Ulrik Jørgensen, Technical University of Denmark, presented the 1994 conference plan, developed by the Nordic working group, including workshop format, a preliminary list of papers to be accepted, and potential speakers. Plans for the 1995 conference, to be held in Toronto, Canada and organised by Professor Nigel Roome, York University, Canada, were presented and discussed. Advisors revised and approved the proposed Network mission and goals document, providing guidance for the coming years. A Network brochure, based on this mission document, is forthcoming. And the advisors participated in the debate at DeBalie, summary above. Comprised of volunteer representatives of academia, government, activists, business, non-governmental organisations and inter-governmental organisations, the board provides a model for the linkages that the Network builds.

\section{CONFERENCE SERIES}

\section{Third International Research Conference \\ From Greening to Sustaining: Transformational Challenges for the Firm Copenhagen, November 13-15, 1994}

We received 120 proposals in response to our December 1993 Call for Papers, sixty of which have been selected for presentation at the next conference. Selection was based on quality, innovation and relevance to the conference themes. The conference will open with two plenary sessions introducing the themes of the conference and addressing the challenges which lie ahead in moving towards sustainability. Plenary sessions will start the subsequent two days of the conference, focusing on issues such as eco-efficiency, public participation, industrial relations and democracy. The plenary sessions will serve as points of departure for further discussion in the workshops. In concurrent workshop sessions, research papers will be presented as an introduction for the workshop discussions. All participants will receive a book of detailed abstracts of papers and discussion themes before the conference. Conference announcements and invitations will be mailed by the end of June.

The Network's fourth international research conference is planned for November 1995 in Toronto, Canada. The Call for Papers will be released later this year.

\section{PUBLICATIONS}

We are pleased to announce that Island Press, publisher of our first book, has expressed its willingness and intention to enter into an agreement with us for a Greening of Industry publication series for edited and single-author books on issues of industry, environment and society. We welcome your proposals for books to be included in the series.

Designing the Sustainable Enterprise - Conference Summary. The conference summary of Designing the Sustainable Enterprise, co-authored by Network participants Nicholas Ashford and Ralph Meima, will be ready for distribution by July, 1994. 1993 conference participants will receive copies of the report. If you did not attend the 1993 conference, and would like to receive a copy, contact one of the Network coordinators.

Bibliography Project: We have received the contract from Island Press for the Greening of Industry Network resource guide and annotated bibliography. a staff of 25 Network editors and authors are presently working on the manuscript for publication of this international, interdisciplinary guide in early 1995.

Environmental Strategies for Industry (1993), our book based on the Network's first international conference, is available from Island Press and Earthscan.

\section{NETWORK}

Our affiliation with Business Strategy and the Environment continues to develop and benefit both the Network and the journal in building a new strategic research area on industry and environment. As part of our developing affiliation, Professor Richard Welford, Editor of Business Strategy and the Environment, has joined the Network's Advisory Board. We are especially pleased to see this special edition which includes ten of the best papers from our 1993 conference, Designing the Sustainable Enterprise. The journal encourages Network members to submit articles for peer-reviewed publication. If you would like to submit a Network NoticeBoard editorial for publication in the journal, please contact Kurt Fischer, clo Tufts University.

Electronic Network: Electronic enquiries regarding the Greening of Industry Network have increased in past months since we have started listing Network news on the US EPA's Gopher service (Gopher: Futures.wic.epa.gov.us and WAIS: 
Wais.com.uslepafutures). Th ise that enquire electronically receive a special questionnaire regarding their use of the Internet. Using their responses, and other sources, we are evaluating options, such as list servers, for developing a Greening of Industry electronic Network. These services would help members find others with similar research interests and allow for on-line collaborative research and writing projects. If you have recommendations for electronic networking, please contact Network coordinator Kurt Fischer.

For further information on the Greening of Industry Network please contact:

Kurt Fischer

Greening of Industry Network

Center for Environmental Management

Tufts University, 177 College Avenue

Medford, Massachusetts, 02155 USA.

tel 6176273846 fax 6176273099

email kfischer@oper.cem.tufts.edu.us

or

Johan Schot

Greening of Industry Network

Centre for Studies of Science Technology and Society

TWr.RC 302, P.O. Box 217, University of Twente

7500 AE Enschede, The Netherlands

tel 3153893344 fax 3153350625

email schot \%fwt \%wmw@civp.utwente.nl 